\title{
Effect of Fagonia Arabica (Dhamasa) on in vitro thrombolysis
} Sweta Prasad ${ }^{1}$, Rajpal Singh Kashyap ${ }^{1}$, Jayant Y Deopujari1, Hemant J Purohit ${ }^{2}$, Girdhar M Taori ${ }^{1}$ and Hatim F Daginawala*1 Address: ${ }^{1}$ Biochemistry Research Laboratory, Central India Institute of Medical Sciences, 88/2, Bajaj Nagar, Nagpur-440010, Maharashtra, India
and ${ }^{2}$ Environmental Genomics Unit, NEERI, Nehru Marg, Nagpur-440020, India

Email: Sweta Prasad - sweta_ciims@yahoo.com; Rajpal Singh Kashyap - raj_ciims@rediffmail.com; Jayant Y Deopujari - jy_deopujari@rediffmail.com; Hemant J Purohit - hemantdrd@rediffmail.com; Girdhar M Taori - taorigm_ciims@yahoo.co.in; Hatim F Daginawala* - hfd_ciims@rediffmail.com

* Corresponding author

Published: 6 November 2007

BMC Complementary and Alternative Medicine 2007, 7:36 doi:10.1 I86/1472-6882-7-36
Received: 15 March 2007

Accepted: 6 November 2007

This article is available from: http://www.biomedcentral.com/1472-6882/7/36

(C) 2007 Prasad et al; licensee BioMed Central Ltd.

This is an Open Access article distributed under the terms of the Creative Commons Attribution License (http://creativecommons.org/licenses/by/2.0), which permits unrestricted use, distribution, and reproduction in any medium, provided the original work is properly cited.

\begin{abstract}
Background: Atherothrombotic diseases such as myocardial or cerebral infarction are serious consequences of the thrombus formed in blood vessels. Thrombolytic agents are used to dissolve the already formed clots in the blood vessels; however, these drugs have certain limitations which cause serious and sometimes fatal consequences. Herbal preparations have been used since ancient times for the treatment of several diseases. Herbs and their components possessing antithrombotic activity have been reported before; however, herbs that could be used for thrombolysis has not been reported so far. This study's aim was to investigate whether herbal preparations (aqueous extract) possess thrombolytic activity or not.

Methods: An in vitro thrombolytic model was used to check the clot lysis effect of six aqueous herbal extracts viz., Tinospora cordifolia, Rubia cordifolia, Hemidesmus indicus, Glycyrrhiza glabra Linn, Fagonia Arabica and Bacopa monnieri Linn along with Streptokinase as a positive control and water as a negative control.

Results: Using an in vitro thrombolytic model, Tinospora cordifolia, Rubia cordifolia, Hemidesmus indicus, Glycyrrhiza glabra Linn, Fagonia Arabica and Bacopa monnieri Linn showed 19.3\%, 14.5\%, $20.3 \%, 17.8 \%, 75.6 \%$ and $41.8 \%$ clot lysis respectively. Among the herbs studied Fagonia arabica showed significant \% of clot lysis $(75.6 \%)$ with reference to Streptokinase $(86.2 \%)$.

Conclusion: Through our study it was found that Dhamasa possesses thrombolytic properties that could lyse blood clots in vitro; however, in vivo clot dissolving properties and active component(s) of Dhamasa for clot lysis are yet to be discovered. Once found Dhamasa could be incorporated as a thrombolytic agent for the improvement of patients suffering from Atherothrombotic diseases.
\end{abstract}

\section{Background}

A blood clot (thrombus) developed in the circulatory system due to failure of hemostasis causes vascular blockage and while recovering leads to serious consequences in atherothrombotic diseases such as myocardial or cerebral infarction, at times leading to death [1]. Thrombolytic agents that include tissue plasminogen activator (t-PA), Urokinase (UK), streptokinase (SK) etc. are used all over 
the world for the treatment of these diseases. In India, though SK and UK are widely used due to lower cost, [2,3] as compared to other thrombolytic drugs, their use is associated with hyper risk of hemorrhage [4] severe anaphylactic reaction and lacks specificity. Moreover, as a result of immunogenicity multiple treatments with SK in a given patient are restricted [5]. Because of the shortcomings of the available thrombolytic drugs, attempts are underway to develop improved recombinant variants of these drugs [6-10].

Herbal products are often perceived as safe because they are "natural" [11]. In India, in recent years, there is increased research on traditional ayurvedic herbal medicines on the basis of their known effectiveness in the treatment of ailments for which they have been traditionally applied.

Considerable efforts have been directed towards the discovery and development of natural products from various plant and animal sources which have antiplatelet [12,13], anticoagulant $[14,15]$, antithrombotic [16], and thrombolytic activity. Epidemiologic studies have provided evidence that foods with experimentally proved antithrombotic effect could reduce risk of thrombosis. Herbs showing thrombolytic activity have been studied and some significant observations have been reported [17].

The aim of present study was to screen aqueous extracts of various herbs viz., Tinospora cordifolia (Guduchi), Rubia cordifolia (Manjistha), Hemidesmus indicus (Anantmool), Glycyrrhiza glabra Linn(Yestimadhu), Fagonia Arabica (Dhamasa) \& Bacopa monnieri Linn (Brahmi) for their clot lysis property (thrombolytic activity) by using an in-vitro procedure.

\section{Methods}

\section{Streptokinase (SK)}

To the commercially available lyophilized SK vial (Polamin Werk GmbH, Herdecke, Germany) of 15, 00,000 I.U., $5 \mathrm{ml}$ sterile distilled water was added and mixed properly. This suspension was used as a stock from which $100 \mu \mathrm{l}(30,000$ I.U) was used for in vitro thrombolysis.

\section{Specimen}

Whole blood $(4 \mathrm{ml})$ was drawn from healthy human volunteers $(n=20)$ without a history of oral contraceptive or anticoagulant therapy (using a protocol approved by the Institutional Ethics Committee of Central India Institute of Medical Sciences, Nagpur). $500 \mu \mathrm{l}$ of blood was transferred to each of the eight previously weighed microcentrifuge tubes to form clots.

\section{Herbal preparation}

Commercially available total extract of herbs, Tinospora cordifolia (guduchi), Rubia Cordifolia (manjistha), Hemidesmus indicus (Anantmool), Glycyrrhiza glabra Linn (yestimadhu) Fagonia arabica (Dhamasa) and Baccopa monnieri (Linn) (brahmi) were purchased from Innocon Foods (Pune, India). The multiple solvent (methanol: isopropyl alcohol: acetone) extraction procedure was used to prepare the extract by the supplier. $100 \mathrm{mg}$ extract was suspended in $10 \mathrm{ml}$ distilled water and the suspension was shaken vigorously on a vortex mixer. The suspension was kept overnight and decanted to remove the soluble supernatant, which was filtered through a 0.22 -micron syringe filter. $100 \mu \mathrm{l}$ of this aqueous preparation of herbs was added to the microcentrifuge tubes containing the clots to check thrombolytic activity.

\section{Clot lysis}

Experiments for clot lysis were carried as reported earlier [18]. In brief, $4 \mathrm{ml}$ venous blood drawn from healthy volunteers was distributed in eight different pre weighed sterile microcentrifuge tube $(0.5 \mathrm{ml} /$ tube $)$ and incubated at $37^{\circ} \mathrm{C}$ for 45 minutes. After clot formation, serum was completely removed without disturbing the clot and each tube having clot was again weighed to determine the clot weight (clot weight $=$ weight of clot containing tube weight of tube alone).

To each microcentrifuge tube containing pre-weighed clot, $100 \mu \mathrm{l}$ of aqueous extract of six herbs (Tinospora cordifolia, Rubia Cordifolia, Hemidesmus indicus, Glycyrrhiza glabra Linn, Fagonia arabica \& Bacopa monnieri (Linn)) was added separately. As a positive control, $100 \mu \mathrm{l}$ of SK and as a negative non thrombolytic control, $100 \mu \mathrm{l}$ of distilled water were separately added to the control tubes numbered. All the tubes were then incubated at $37^{\circ} \mathrm{C}$ for 90 minutes and observed for clot lysis. After incubation, fluid released was removed and tubes were again weighed to observe the difference in weight after clot disruption. Difference obtained in weight taken before and after clot lysis was expressed as percentage of clot lysis. The experiment was repeated 20 times with the blood samples of 20 volunteers.

\section{Statistical analysis}

The significance between \% clot lysis by Streptokinase and herbal extract by means of weight difference was tested by the paired t-test analysis. Data are expressed as mean \pm standard deviation.

\section{Results}

Addition of $100 \mu \mathrm{l} \mathrm{SK}$, a positive control (30,000 I.U.) to the clots along with 90 minutes of incubation at $37^{\circ} \mathrm{C}$, showed $86.2 \%$ clot lysis. Clots when treated with $100 \mu \mathrm{l}$ sterile distilled water (negative control) showed only neg- 
ligible clot lysis (4.7\%). The mean difference in clot lysis percentage between positive and negative control was very significant ( $\mathrm{p}$ value $<0.0009$ ). After treatment of clots with $100 \mu \mathrm{l}$ of Tinospora cordifolia, Rubia cordifolia, Hemidesmus indicus, Glycyrrhiza glabra Linn, negligible clot lysis i.e., $19.3 \%, 14.5 \%, 20.3 \%, 17.8 \%$ respectively was obtained but mean of percentage of clot lysis was more than water. But when $100 \mu \mathrm{l}$ Fagonia arabica and Bacopa monnieri were added to two different clots, $75.6 \%$ and $41.8 \%$ clot lysis was obtained respectively and when compared with the negative control (water) the mean clot lysis $\%$ difference was significant ( $\mathrm{p}$ value $<0.0001 \&=0.0023$ respectively). Percent clot lysis obtained after treating clots with different herbs and appropriate controls is shown in Figure 1. Statistical representation of the effective clot lysis percentage by six herbal preparations, positive thrombolytic control (Streptokinase) and negative control (sterile distilled water) is tabulated in Table 1.

\section{Discussion}

Herbal preparations are used since ancient times to maintain health and regain healthy state of mind. Advances in phytochemistry and identification of plant compounds, which are effective in curing certain diseases have renewed the interest in herbal medicines. About $30 \%$ of the pharmaceuticals are prepared from plants worldwide [19]. A number of studies have been conducted by various researchers to find out the herbs and natural food sources and their supplements having antithrombotic (anticoagulant and antiplatelet) effect and there is evidence that consuming such food leads to prevention of coronary events and stroke [20-23]. There are several thrombolytic drugs obtained from various sources. Some are modified further with the use of recombinant technology [24] in order to make these thrombolytic drugs more site specific and effective. Side effects related to these drugs have been reported that lead to further complications [25]. Sometimes the patients die due to bleeding and embolism [24,26-28].

Herbal preparations, if taken in appropriate dose, can lead to a better option for curing various ailments. Toxicity of plant extract is a major concern of scientists and medical practitioners. Among several methods lethality test has

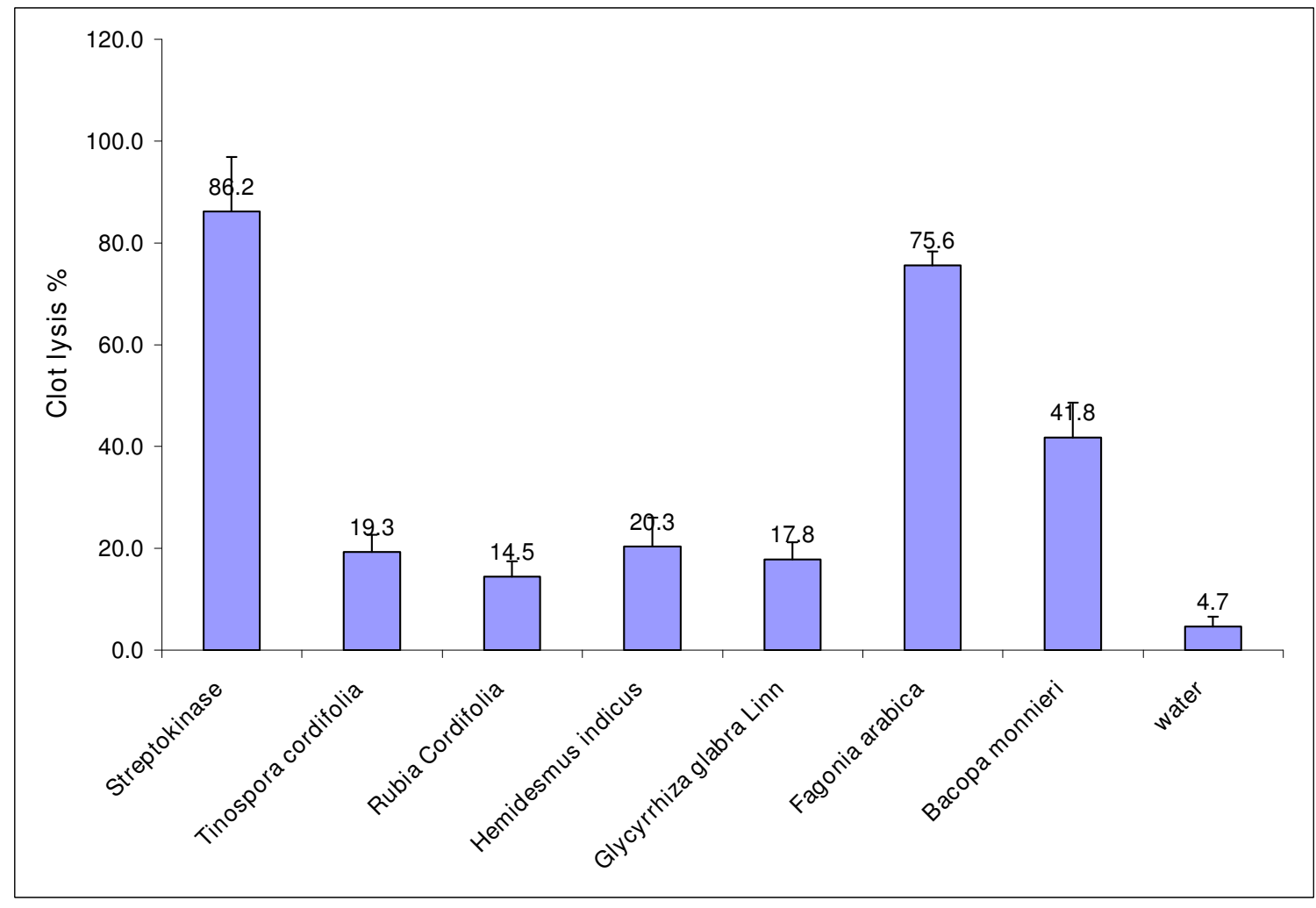

\section{Figure I}

Clot lysis by Streptokinase, water and various herbal preparations. Effects of drugs on dissolution of clots prepared from blood of normal individuals. Maximum clot lysis was observed in clot treated with streptokinase (SK). Among herbal drugs Fagonia arabica (Dhamasa) showed 75.6\% clot lysis. Bacopa monnieri Linn (Brahmi) showed $41.8 \%$ clot lysis. Water (as a negative control) showed $4.7 \%$ clot lysis. With other herbs negligible clot lysis was observed. 
Table I: Effect of six different herbal extracts $(10 \mathrm{mg} / \mathrm{ml})$ on in vitro clot lysis.

\begin{tabular}{ccc}
\hline Herbs/Drugs & $\begin{array}{c}\text { Mean } \pm \text { S.D. } \\
\text { (Clot lysis \%) }\end{array}$ & $\begin{array}{c}\text { Pvalue when compared to } \\
\text { negative control (water) }\end{array}$ \\
\hline Streptokinase & $86.2 \pm 10.7$ & $<0.0009$ \\
Fagonia arabica & $75.6 \pm 2.7$ & $<0.0001$ \\
Tinospora cordifolia & $19.3 \pm 3.4$ & 0.0045 \\
Rubia cordifolia & $14.5 \pm 3$ & 0.0231 \\
Hemidesmus indicus & $20.3 \pm 5.7$ & 0.0072 \\
Glycyrrhiza glabra Linn & $17.8 \pm 3.4$ & 0.0115 \\
Bacopa monnieri & $41.8 \pm 6.8$ & 0.0023
\end{tabular}

Statistical representation of the effective clot lysis percentage by six herbal preparations, positive thrombolytic control (Streptokinase) and negative control (sterile distilled water) done by paired t-test analysis; clot lysis $\%$ is represented as mean \pm S.D. and a $p$ value $<0.05$ was considered as significant.

been successfully used to biomonitor the isolation of cytotoxic, antimalarial, insecticidal and antifeedants compounds from plant extracts [29]. In this aspect toxicity of plant extract could be beneficial to mankind however, if taken in higher/lethal dose plant extracts could be harmful $[30,31]$. Several lethality tests have been designed and one such method is the lethality test wherein Brine Shrimp Lethality (LC50, $24 \mathrm{hr}$.) test has been used to determine cytotoxicity which has shown toxicity of Fagonia arabica to be $900 \mu \mathrm{g} / \mathrm{ml}$ [29].

In our study of thrombolysis we have tried six herbal preparations that are used since ancient times for neuroprotection and for curing vascular diseases (Table 2). For example, Hemidesmus indicus was reported to have antithrombotic activity [32]. The roots of Rubia cordifolia are used internally in the treatment of abnormal uterine bleeding, as well as for internal and external haemorrhage [33]. Bacopa monnieri Linn is used for the treatment of stroke and Alzheimer disease [34]. Glycyrrhiza glabra Linn was reported to have antiplatelet and anti-inflammatory activity [35]. Fagonia arabica is known to have blood puri-

Table 2: List of herbal preparations used in the study and related medicinal uses.

\begin{tabular}{|c|c|c|}
\hline S. No. & Herbal preparation & Medicinal use \\
\hline I & Fagonia arabica & blood purifier, deobstruent \\
\hline 2 & Bacopa monnieri & $\begin{array}{c}\text { treatment of stroke and Alzheimer } \\
\text { disease }\end{array}$ \\
\hline 3 & Tinospora cordifolia & neuroprotection \\
\hline 4 & Hemidesmus indicus & antithrombotic activity \\
\hline 5 & Glycyrrhiza glabra Linn & $\begin{array}{c}\text { antiplatelet and anti-inflammatory } \\
\text { activity }\end{array}$ \\
\hline 6 & Rubia cordifolia & $\begin{array}{c}\text { used internally in the treatment of } \\
\text { abnormal uterine bleeding, as well } \\
\text { as for internal and external } \\
\text { haemorrhage }\end{array}$ \\
\hline
\end{tabular}

fying property [36]. Tinospora cordifolia along with Fagonia arabica and Rubia cordifolia was reported to exert neuroprotection [37]. The aim of this study was to check if these herbal preparations posses clot lytic activity.

SK, a known thrombolytic drug [38] is used as a positive control. Water, on the other hand, was selected as a negative control. The comparison of positive control with negative control clearly demonstrated that clot dissolution does not occur when water was added to the clot. The percentage of clot lysis by both these controls differ significantly as the p value was 0.0009 (test was extremely significant). Encouraged by the results obtained through the clot lysis activity by SK and with water as a negative control we tried six herbal preparations in the same manner. When compared with the clot lysis percentage obtained through water (negative control), a significant thrombolytic activity was observed after treating the clots with Fagonia arabica extract $(75.6 \%$; p value $<0.0001)$.

Fagonia arabica belongs to Zygophyllaceae family [39] and is known as 'Kharasan' thorn in English and by a common name of "Dhamasa" in India. It is a green shrub of 1 to 3 feet height, found on calcareous rocks distributed throughout the Mediterranean region of South Africa, Afghanistan, India (Rajasthan, northwest Punjab, and Western India), and Pakistan (Sindh, Punjab, North-West Frontier Province, NWFP) [40]. The whole plant is used for medical purpose; popularly known in hilly areas as a fever remedy source. Infusion is effective as cooling agent in stomatitis. It is known to purify blood and also acts as a deobstruent [36]. It is also used for skin diseases, small pox and for endothermic reaction in the body [41]. The twigs of the plant are used as remedy for snake bite and also applied externally as paste on tumors and for the swellings of neck [39-41].

Interestingly Bacopa monnieri Linn exhibited nearly $50 \%$ of clot lysis. So far, researchers have reported the use of nitric oxide from Bacopa monnieri Linn in the treatment of stroke and Alzheimer's sufferers. Moreover, it has been valued as a cardiac, nerve and brain tonic [34].

There are few plant extracts/products which have been identified to have fibrinolytic activity. These are Lumbricus rubellus [42], Pleurotus ostreatus [43], Spirodela polyrhiza [44], Flammulina velutipes [45], and Ganoderma lucidum [46], Ginger (Zingiber officinale) [47], Garlic (Allium sativum) [48], Saffron \{Crocus sativus Linn (indraceae) \} [49] as well as from Bacillus sp. in Korean and Japanese fermented foods, chungkook-jang [50] and natto [51,52] respectively. Most of these are enzymes which closely resembles serine proteases like plasmin as these are relatively specific to fibrin or fibrinogen as a protein substrate. In general, blood clots are formed from fibrinogen by 
thrombin and are lysed by plasmin, which is activated from plasminogen by a tissue plasminogen activator. However, there is one marine brown algae product called Seanol (phlorotannin - active compound), have a unique property in promotion of dissolution of intravascular blood clot via antiplasmin inhibition [53].

Fagonia arabica is known to have antibacterial activity [29] which is done against two strains of bacteria notably, Escherichia coli and Staphylococcus aureus [54]. However, there are reports of bacterial contaminants of plants which have plasminogen receptors that bind plasminogen. Cell surface bound plasminogen is easily activated to plasmin, which could lead to fibrinolysis [55]. Bacterial plasminogen activator: staphylokinase, streptokinase, act as cofactor molecules that contribute to exosite formation and enhance the substrate presentation to the enzyme. Staphylokinase activates plasminogen to dissolve clots, also destroys the ECM and fibrin fibers that hold cells together $[56,57]$.

In context of the above discussion it would be interesting to investigate the causative components/mechanism for clot lysis by Fagonia arabica and Bacopa monnieri Linn extract with respect to its toxicity, bacterial contamination, plasmin activation, inhibitors of antiplasmins, or phytochemicals/secondary metabolites.

\section{Conclusion}

In conclusion, on the basis of beneficial effect of Fagonia arabica (Dhamasa) in the literature and our own results of the experiments in the extract of same herb, Fagonia arabica lyses blood clots in vitro; however, in vivo clot dissolving property and active component(s) of Dhamasa for clot lysis are yet to be found out. Once found Dhamasa may be incorporated as a thrombolytic agent for the improvement of the patients suffering from Atherothrombotic diseases.

\section{Competing interests}

The author(s) declare that they have no competing interests.

\section{Authors' contributions}

SP carried out the study design, experiments, data collection, data interpretation, literature search and manuscript preparation. RSK and HJP participated in study design, experiments, data interpretation, and literature search and manuscript preparation. JYD provided all the details on herbs and ayurvedic literature. GMT provided assistance in preparation of the manuscript, data interpretation, study design and collecting funds. HFD supervised the study design, statistical analysis, data interpretation, manuscript preparation and literature search. All authors read and approved the final version of the manuscript.

\section{Acknowledgements}

We thank Prashant D. Deoras for assistance in statistical analysis.

\section{References}

I. Lee HS: How safe is the readministration of streptokinase. Drug Saf 1995, 13:76-80.

2. Mucklow JC: Thrombolytic treatment - streptokinase is more economical than Alteplase. BMJ 1995, 3 I I: I506.

3. Collen D: Coronary thrombolysis: streptokinase or recombinant tissue-type plasminogen activator? Ann Intern Med 1990, I | 2:529-538.

4. Rouf SA, Moo-Young M, Chisti Y: Tissue-type plasminogen activator: characteristics, applications and production technology. Biotechnol Adv 1996, 14:239-266.

5. Jennings K: Antibodies to streptokinase - once is enough. $B M J$ | 996, 3 | 2:393-394.

6. Nicolini FA, Nichols WW, Mehta JL, Saldeen TG, Schofield R, Ross M, Player DW, Pohl GB, Mattsson C: Sustained reflow in dogs with coronary thrombosis with $\mathrm{K2P}$, a novel mutant of tissue plasminogen activator. J Am Coll Cardiol 1992, 20:228-235.

7. Adams DS, Griffin LA, Nachajko WR, Reddy VB, Wei CM: A synthetic DNA encoding a modified human urokinase resistant to inhibition by serum plasminogen activator inhibitor. J Biol Chem 1991, 266:8476-8482.

8. Lijnen HR, Vanhoef B, DeCock F, Okada K, Ueshima S, Matsuo O: On the mechanism of fibrin-specific plasminogen activation by staphylokinase. J Biol Chem I991, 266: I I826-I I832.

9. Marder VJ: Recombinant streptokinase - opportunity for an improved agent. Blood Coagul Fibrinolysis 1993, 4:1039-1040.

10. Wu DH, Shi GY, Chuang WJ, Hsu JM, Young KC, Chang CW: Coiled coil region of streptokinase gamma-domain is essential for plasminogen activation. J Biol Chem 2001, 276: I 5025-I5033.

II. Gesler WM: Therapeutic landscapes: medical issues in light of the new cultural geography. Soc Sci Med 1992, 34:735-746.

12. Demrow HS, Slane PR, Folts JD: Administration of wine and grape juice inhibits in vivo platelet activity and thrombosis in stenosed canine coronary arteries. Circulation 1995, 9 I (4): I | 82-I | 88.

13. Briggs WH, Folts JD, Osman HE: Administration of raw onion inhibits platelet-mediated thrombosis in dogs. J Nutr 200I, I 3 I ( I 0):2619-2622.

14. Leta GC, Mourão PA, Tovar AM: Human venous and arterial glycosaminoglycans have similar affinity for plasma low-density lipoproteins. Biochim Biophys Acta 2002, I 586(3):243-253.

15. Zhiguang LI, WANG Hongli, Jiazeng LI, Guangshen ZHANG, Cunji Gao: Basic and clinical study on the antithrombotic mechanism of glycosaaminoglycan extracted from sea cucumber. Chin Med J 2000, I I3(8):706-7II.

16. Rajapakse N, Jung WK, Mendis E, Moon SH, Kim SK: A novel anticoagulant purified from fish protein hydrolysate inhibits factor XIla and platelet aggregation. Life Sciences 2005, 76(22):2607-2619.

17. Yamamoto J, Yamada K, Naemura A, Yamashita T, Arai R: Testing various herbs for antithrombotic effect. Nutrition 2005, 2 I (5):580-587.

18. Prasad S, Kashyap RS, Deopujari JY, Purohit HJ, Taori GM, Daginawala HF: Development of an in vitro model to study clot lysis activity of thrombolytic drugs. Thrombosis Journal 2006, 4:14.

19. Anwar AK, Ashfaq M, Nasveen MA: Pharmacognostic studies of selected indigenous plants of Pakistan. Pakistan Forest Institute, Peshawar NWFP, Pakistan; 1979:I5-35.

20. Gillman MW, Cupples LA, Gagnon D, Posner BM, Ellison RC, Castelli WP, Wolf PA: Protective effect of fruits and vegetables on development of stroke in men. JAMA 1995, 273:III3-III 7.

21. Joshipura KJ, Ascherio A, Manson JE, Stampher MJ, Rimm EB, Speizer $\mathrm{FE}$ : Fruit and vegetable intake in relation to risk of ischemic stroke. JAMA 1999, 282:1233-I239.

22. Liu S, Manson JE, Lee I-M, Cole SR, Hennekens CH, Willett WC, Buring JE: Fruit and vegetable intake and risk of cardiovascular disease: the Women's Health Study. Am J Clin Nutr 2000, 72:922-928.

23. Bazzano LA, He J, Ogden LG, Loria CM, Vupputuri S, Myers L, Whelton PK: Fruit and vegetable intake and risk of cardiovascular disease in US adults: the first National Health and Nutrition 
Examination Survey Epidemiologic Follow-up Study. Am J Clin Nutr 2002, 76:93-99.

24. Verstraete M: Third generation thrombolytic drugs. Am J Med 2000, I09(I):52-58

25. Baruah DB, Dash RN, Chaudhari MR, Kadam SS: Plasminogen activators: A comparison. Vascular pharmacology 2006, 44: I-9.

26. Gallus AS: Thrombolytic therapy for venous thrombosis \& pulmonary embolism. Bailliere's Clinical Haematology 1998, I I(3):663-673.

27. Wardlaw JM, Berge E, del Zoppo G, Yamaguchi T: Thrombolysis for acute ischemic stroke. Stroke 2004, 35:2914-29I5.

28. Capstick T, Henry MT: Efficacy of thrombolytic agents in the treatment of PE. Eur Respir J 2005, 26:864-874.

29. Krishnaraju AV, Rao TVN, Sundararaju D, Vanisree M, Tsay H-S, Subbaraju GV: Biological screening of medicinal plants collected from Eastern Ghats of India using Artemia salina (Brine Shrimp Test). Int J Appl Sci Eng 2006, 4(2): I I5- I 25.

30. Okwuosa VN, Molta BS, Ebele S: Toxicity of aqueous bark extract of the tree Balanites aegyptiaca on the fish Oreochromis niloticus. Appl Parasitol 1993, 34(2):89-94.

31. Nikai T, Mori N, Kishida M, Sugihara H, Tu AT: Isolation and biochemical characterization of hemorrhagic toxin $f$ from venom of Crotalus atrox. Arch Biochem Biophys 1984, 231:309-319.

32. Mary NK, Achuthan $\mathrm{CR}$, Babu $\mathrm{BH}$, Padikkala J: In vitro antioxidant and antithrombotic activity of Hemidesmus indicus (L) R.Br. J Ethnopharmacol 2003, 87:2-3.

33. Bown D: Encyclopedia of Herbs and their Uses Dorling Kindersley, London; 1995. ISBN 0-75|3-020-31.

34. Joshi $\mathrm{H}$, Parle $\mathrm{M}$ : Brahmi rasayana improves learning and memory in mice. Evid Based Complement Alt Med 2006, 3(I):79-85.

35. Kharb S, Singh V: Nutriceuticals in health and disease prevention. Ind J Clin Biochem 2004, I (1):50-53.

36. Said HM: Medicinal herbal - a textbook for medical students and doctors. Volume I. Hamdard Foundation Nazimabad, Karachi74600 Sindh, Pakistan; 1996.

37. Rawal AK, Muddeshwar MG, Biswas SK: Rubia cordifolia, Fagonia cretica linn and Tinospora cordifolia exert neuroprotection by modulating the antioxidant system in rat hippocampal slices subjected to oxygen glucose deprivation. BMC Complement Altern Med 2004, 4: II

38. Tillet WS, Garner RL: The fibrinolytic activity of hemolytic streptococci. J Exp Med 1933, 58:485-502.

39. Hooker JD: Flora of British India Volume 3. Reeve and Co. London; I 882:640.

40. Rizvi MA, L. Ahmad, Sarwar GR: Wild medicinal plants of Medinatul Hikmah and its Adjacent Areas. Hamdard Medicus 1996, 39:8-10.

4I. Watt G: Dictionary of the Economic Products of India. Periodical Experts, 42-D, Vivek Vihar, Shahdara, Delhi, India 1972, I:444-446.

42. Jeon O-H, Moon W-J, Kim D-S: An anticoagulant/fibrinolytic protease from Lumbricus rubellus. J Biochem Molec Biol 1995 , 28: $138-142$

43. Choi HS, Shin HH: Purification and characterization of a fibrinolytic protease in Pleurotus ostreatus. Mycologia 1998, 90:674-679.

44. Choi HS, Sa YS: Fibrinolytic and antithrombotic protease from Spirodela polyrhiza. Biosci Biotechnol Biochem 200I, 65(4):78I-786.

45. Shin $\mathrm{HH}$, Choi HS: Purification and partial characterization of a metalloprotease in Flammulina velutipes. I Microbiol 1998, 36:20-25.

46. Choi HS, Sa YS: Fibrinolytic and antithrombotic protease from Ganoderma lucidum. Mycologia 2000, 92:545-552.

47. Verma SK, Bordia A: Ginger, fat and fibrinolysis. Indian J Med Sci 200I, 55:83-86.

48. Bordia A, Verma SK, Srivastava KC: Effect of garlic (Allium sativum) on blood lipids, blood sugar, fibrinogen and fibrinolytic activity in patients with coronary artery disease. Prostaglandins Leukot Essent Fatty Acids 1998, 58(4):257-263.

49. [http://www.himalayadirect.com/shopcontent.asp?type=h crocus].

50. Kim W, Choi K, Kim Y, Park H, Choi J, Lee Y, Oh H, Kwon I, Lee S: Purification and characterization of a fibrinolytic enzyme produced from Bacillus Sp. strain CK II-4 screened from chungkook-jang. Appl Environ Microbiol 1996, 62:2482-2488.
5I. Sumi $\mathrm{H}$, Hamada $\mathrm{H}$, Tsushima $\mathrm{H}$, Mihara $\mathrm{H}$, Muraki $\mathrm{H}$ : A novel fibrinolytic enzyme in the vegetable cheese Natto; a typical and popular soybean food in the Japanese diet. Experimentia 1987, 43: III0-IIII.

52. Sumi $H$, Hamada $H$, Nakanishi K, Hiratani H: Enhancement of the fibrinolytic activity in plasma by oral administration of NK. Acta Haematol 1990, 84: 139-143.

53. [http://www.jprenew.com/documents/app A/ SEANOL APPLICATIONS RESEARCH OVERVIEW.pdf].

54. Elshanta N, Eshtewi A, Elmigirab S, Auzi A: Antibacterial activity of Fagonia arabica L. abstract no. 3-2-4: [http://7ou.edu.ly/ sixth final program.pdf]. Article last accessed on 07-09-2007

55. Pantzar $M$, Ljungh $A$, Wadström T: Plasminogen binding and activation at the surface of Helicobacter pylori CCUG 17874. Infect Immun 1998, 66(10):4976-4980.

56. Parry MA, Zhang XC, Bode I: Molecular mechanisms of plasminogen activation: bacterial cofactors provide clues. Trends Biochem Sci 2000, 25(2):53-59.

57. Collen D: Staphylokinase: a potent, uniquely fibrin-selective thrombolytic agent. Nat Med 1998, 4(3):279-284.

\section{Pre-publication history}

The pre-publication history for this paper can be accessed here:

http://www.biomedcentral.com/1472-6882/7/36/prepub

Publish with BioMed Central and every scientist can read your work free of charge

"BioMed Central will be the most significant development for disseminating the results of biomedical research in our lifetime. "

Sir Paul Nurse, Cancer Research UK

Your research papers will be:

- available free of charge to the entire biomedical community

- peer reviewed and published immediately upon acceptance

- cited in PubMed and archived on PubMed Central

- yours - you keep the copyright

Submit your manuscript here:

http://www.biomedcentral.com/info/publishing_adv.asp
BioMedcentral 